\title{
Häberlein, Mark, Kuhn, Christian, Hörl, Lina, Generationen in spätmittelalterlichen und frühneuzeitlichen Städten (ca. 1250-1750)
}

\section{Aude-Marie Certin}

\section{CpenEdition}

\section{Journals}

Édition électronique

URL : http://journals.openedition.org/ifha/6748

DOI : $10.4000 /$ ifha. 6748

ISSN : 2198-8943

Éditeur

IFRA - Institut franco-allemand (sciences historiques et sociales)

Référence électronique

Aude-Marie Certin, « Häberlein, Mark, Kuhn, Christian, Hörl, Lina, Generationen in spätmittelalterlichen und frühneuzeitlichen Städten (ca. 1250-1750) », Revue de l'IFHA [En ligne], Date de recension, mis en ligne le 01 janvier 2012, consulté le 22 septembre 2020. URL : http://journals.openedition.org/ifha/ 6748 ; DOI : https://doi.org/10.4000/ifha.6748

Ce document a été généré automatiquement le 22 septembre 2020.

(C)IFHA 


\title{
Häberlein, Mark, Kuhn, Christian, Hörl, Lina, Generationen in spätmittelalterlichen und frühneuzeitlichen Städten (ca. 1250-1750)
}

\author{
Aude-Marie Certin
}

1 Fruit d'une rencontre organisée à Bamberg en février 2009 dans le cadre du Graduiertenkolleg portant sur le thème "Conscience des générations et conflits des générations à l'époque antique et au Moyen Âge ", cet ouvrage collectif traite des générations dans les villes à la fin du Moyen Âge et à l'époque moderne. S'y trouvent ainsi articulées deux perspectives de recherche généralement considérées de façon séparée, à savoir l'histoire des générations et l'histoire urbaine. Cet ouvrage commence par une excellente introduction de M.H. et Ch.K. sur les concepts et les approches de l'histoire des générations depuis Karl Mannheim qui envisagea le concept dans une optique synchronique et horizontale, aux études les plus récentes qui en proposent une approche plus diachronique, en posant notamment la question du rapport entre les générations. Associant de fait ces deux dimensions, l'approche revendiquée dans cet ouvrage est celle de l'empirisme. Sans proposer une définition déterminée de la notion de génération, ce recueil cherche plutôt à tester la portée et la pertinence de celle-ci à travers des cas concrets, envisagés dans des contextes divers et à travers des problématiques variées.

2 Du point de vue géographique, la thématique est abordée dans l'espace germanique mais aussi en Italie, en France et en Angleterre, sur une période large allant du XIIIe siècle au XVIIIe siècle. B. Scheller étudie la transmission intergénérationnelle dans le milieu des Juifs convertis dans la ville italienne de Trani à la fin du XIIIe siècle. Partant $\mathrm{du}$ cas des Medici, H. Lang montre pour sa part toute l'importance de la relation pèrefils dans la conscience générationnelle à Florence au XVe siècle, ce dont témoignent 
testaments, écrits de mémoire et lettres qui contribuent à construire une conscience généalogique basée sur la patrilinéarité. $M$. Schuh interroge quant à lui la notion de conflit intergénérationnel dans le cadre des conflits entre « vieux » bourgeois et jeunes étudiants d'Ingolstadt à la fin du Moyen Âge. Dans un article particulièrement intéressant, Ch.K. se penche sur les valeurs véhiculées dans l'écriture de l'histoire familiale au temps de la Renaissance, en partant du Livre de la famille d'Alberti pour se pencher ensuite sur la façon dont le discours sur la génération est élaboré à Nuremberg au début du XVIe siècle dans les écrits de Christoph Scheurl et dans les nombreux livres de famille produits dans cette ville à cette époque. B. Schneider étudie les procès que certains membres de la grande famille des Fugger d'Augsbourg mènent contre d'autres membres de la famille dans les années 1560 , rompant ainsi avec la règle jusque-là dominante de régler les affaires de biens et d'héritage de la famille sans recourir à la voie juridique. M.H. s'intéresse quant à lui aux conflits entre générations tels qu'on les voit percer au sein des lettres échangées entre père et fils dans le milieu patricien des villes d'Empire au début du XVIIe siècle. Étudiant plusieurs pièces de Corneille, P. Cl. Doering montre comment les changements dans les valeurs et la morale caractérisant la France du XVIIe siècle s'y trouvent mis en scène en tant que conflits de générations. C. Flügge se propose de montrer que la restauration de la monarchie anglaise dans les années 1660 peut aussi être comprise sous l'angle d'un changement de génération. G. Ingendahl étudie pour sa part le statut des veuves à Ratisbonne au début de l'époque moderne, montrant qu'elles jouent un rôle essentiel dans la transmission des biens du foyer d'une génération à l'autre en assurant la bonne tenue de la maison et des affaires de la famille après la mort du père.

Depuis quelques années, la question des générations est l'objet d'un fort regain d'intérêt en Allemagne (voir la recension de l'ouvrage de Ch. Kuhn, Generation als Grundbegriff einer historischen Geschichtskultur. Die Nürnberger Tucher im langen 16. Jahrhundert, 2010, dans la RevIFHA, 2011), et cet ouvrage fait indéniablement partie des publications importantes de ces dernières années sur ce thème. On regrettera seulement l'absence d'une conclusion qui aurait pu offrir une mise en perspective globale sur la problématique des générations dans les villes à l'époque médiévale et moderne. Il n'en demeure pas moins que ce recueil propose des études de cas aussi précises que variées, apportant ainsi une matière riche et des réflexions stimulantes sur la question.

Aude-Marie CERTIN (IFHA) 